\title{
Correction to: CEPO (carbamylated erythropoietin)-Fc protects hippocampal cells in culture against beta amyloid-induced apoptosis: considering Akt/GSK-3 $\beta$ and ERK signaling pathways
}

\author{
Etrat Hooshmandi ${ }^{1,2} \cdot$ Maryam Moosavi $^{3} \cdot$ Hermann Katinger $^{4} \cdot$ Shima Sardab $^{5} \cdot$ Rasoul Ghasemi $^{6}$ (D) \\ Nader Maghsoudi, ${ }^{1,7}$
}

Published online: 20 May 2020

(c) Springer Nature B.V. 2020

\section{Correction to: Molecular Biology Reports https://doi.org/10.1007/s11033-020-05309-6}

Unfortunately, the original version of this article contained a mistake in the arrangement of representative cell images in Fig. 2. In this figure, the same representative image for $A \beta$ group was mistakenly placed for $A \beta+L Y$ group. The corrected form of Fig. 2 is provided in this correction.

The original article can be found online at https://doi.org/10.1007/ s11033-020-05309-6.

Rasoul Ghasemi rghasemi60@sbmu.ac.ir

$\triangle$ Nader Maghsoudi

Nmaghsoudi@sbmu.ac.ir

1 Neuroscience Research Center, Shahid Beheshti University of Medical Sciences, Tehran, Iran

2 Clinical Neurology Research Center, Shiraz University of Medical Sciences, Shiraz, Iran

3 Nanobiology and Nanomedicine Research Centre, Shiraz University of Medical Sciences, Shiraz, Iran

4 Department of Biotechnology, University of Natural Resources and Life Sciences, Vienna, Austria

5 Biology Department, University of Tehran, Tehran, Iran

$6 \quad$ Neurophysiology Research Center and Physiology Department, Shahid Beheshti University of Medical Sciences, Tehran, Iran

7 Neurobiology Research Center, Shahid Beheshti University of Medical Sciences, Tehran, Iran 


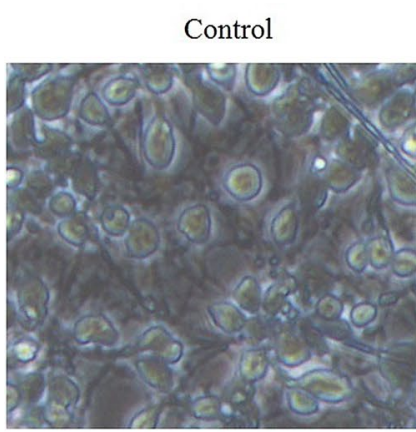

$\mathrm{A} \beta+\mathrm{LY}$

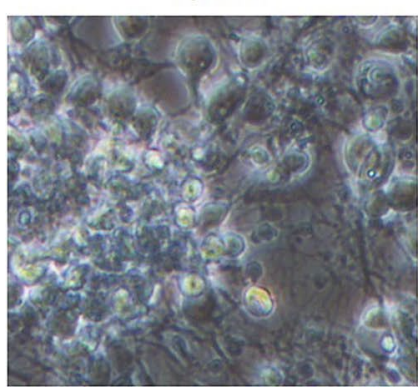

$\mathrm{A} \beta 20 \mu \mathrm{M}$

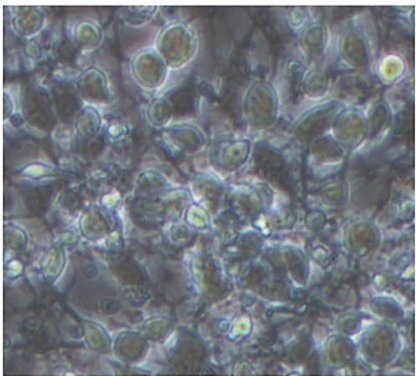

$\mathrm{A} \beta+\mathrm{CEPO}-\mathrm{Fc} 5 \mathrm{IU}+\mathrm{PD}$

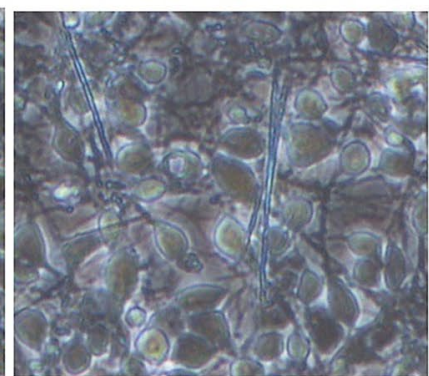

$\mathrm{A} \beta+\mathrm{CEPO}-\mathrm{Fc} 5 \mathrm{IU}$

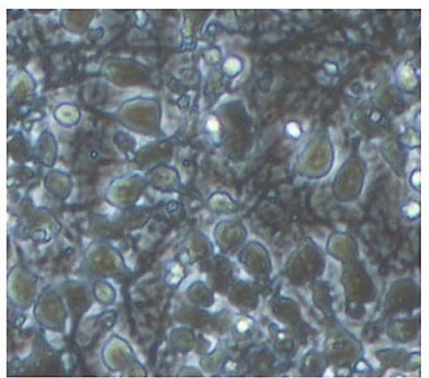

$\mathrm{A} \beta+\mathrm{PD}$

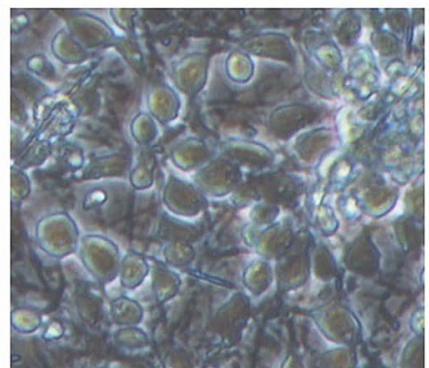

$\mathrm{A} \beta+\mathrm{CEPO}-\mathrm{Fc} 5 \mathrm{IU}+\mathrm{LY}$

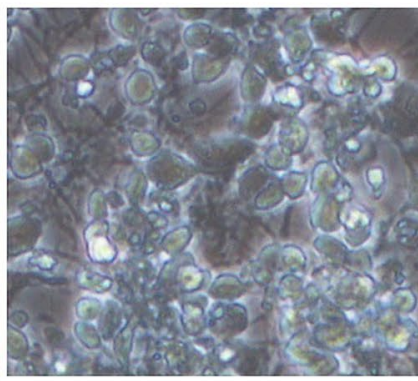

CEPO-Fc5IU

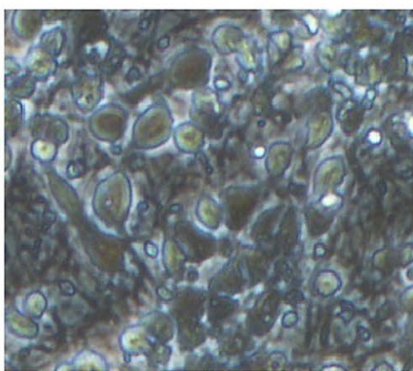

Fig. 2 The representative images of morphological changes of hippocampal cells in different groups $24 \mathrm{~h}$ after cell treatments

Publisher's Note Springer Nature remains neutral with regard to jurisdictional claims in published maps and institutional affiliations. 